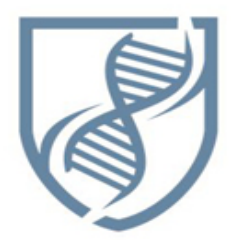

Journal of Bioscience and Applied Research

\section{JBAAR}

WWW.JBAAR.ORG

\title{
Study of the effect of silver nanoparticles encapsulated by doxorubicin drug in the treatment of hepatocellular carcinoma
}

\author{
Rasha Said Shams El-Dine ${ }^{1}$, Samir Ali Abd El Kaream² \\ ${ }^{1}$ Medical Biophysics Department, Medical Research Institute, Alexandria University \\ ${ }^{2}$ Applied Medical Chemistry Department, Medical Research Institute, Alexandria University \\ E.mail:rasha_shams17@yahoo.com
}

\begin{abstract}
Hepatocellular carcinoma (HCC) is the third deadliest and fifth most common cancer worldwide. Many drugs that have the potential to treat cancers have had limited success due to their lack of efficient and safe delivery mechanisms that allow the drug molecules to cross cell membranes. Electrical pulses-mediated drug delivery, known as electroporation, is gaining attention as a possible approach to enhance uptake of chemotherapy. The present work studied the effect of silver nanoparticles encapsulated by doxorubicin drug in the treatment of hepatocellular carcinoma. The study was conducted on 40 albino mice weighting 20-25 g of 8-10 weeks of age, and were divided into two major groups. Group A:10 mice were used as a control, group B: 40 mice have induced HCC by DABE this group were subdivided into three subgroups; sub groupB1 10 mice which were not received any treatment, and were kept at room environment and, sub group B2: 10 mice were injected i.p with a dose of 50 $\mathrm{mg} / \mathrm{kg}$ body weight of doxorubicin only every day for 21days, sub group B3:10 mice were injected i.p. with a dose of $50 \mathrm{mg} / \mathrm{kg}$ body weight of doxorubicin encapsulated by the silver nanoparticles every day for 21days.Parts of liver tissue and blood samples were collected from all from mice of each group for histopathological examination; the nanocapsules were of the size range $200 \pm 20 \mathrm{~nm}$ and loaded with the positively charged anticancer drug doxorubicin with an efficiency of $89 \%$. The loading of the drug into the capsule occurs by virtue of the $\mathrm{pH}$-responsive property of the capsule wall, which is determined by the $\mathrm{pKa}$ of the polyelectrolytes. As the $\mathrm{pH}$ is varied, about $64 \%$ of the drug is released in acidic $\mathrm{pH}$ while $77 \%$ is released in neutral $\mathrm{pH}$. Molecular detection of Alpha-fetoprotein (AFP)
\end{abstract}

and Glypican-3 (gly3) mRNAs by RT-PCR before and after treatment by silver nanoparticles encapsulated doxorubicin drug were studied in mice with HCC. Silver nanoparticles encapsulated doxorubicin drug showed effective results for treatment of HCC compared to results obtained with doxorubicin drug resulting in reduced tumor growth, and induction of apoptosis in the treated cells by enhancing of delivering chemotherapy and anticancer drugs with enhanced efficacy and fewer adverse effects.

Keywords: Silver nanoparticles, Doxorubicin, AFPmRNA, gly3 mRNA, Hepatocellular carcinoma

\section{Introduction}

According to Globocan 2000, "Hepatocellular carcinoma (HCC) is the fifth most common solid tumor worldwide and the fourth leading cause of cancer-related death," with an estimated death rate of more than 500,000 per year. Parkin et al. (2000) reported that the disease is usually detected when the tumor is in an advanced stage and surgical resection is in most cases no longer feasible. Liver transplantation is normally the best option, as long as the patient still falls within the Milan criteria (Bruix et al.2005). Without surgical intervention, survival depends on the amount of healthy liver tissue remaining in comparison with cirrhotic or malignant tissue (ChildPugh grade and tumor stage)(Yang et al. 2010). The infection along with alcohol and aflatoxin B1 intake are widely recognized etiological agents in HCC (Wild et al. 2000). However, the underlying mechanisms that lead to malignant transformation of infected cells remain unclear (Anwar et al. 2008). Most of HCC patients died quickly because of the rapid tumor progression, and hepatic resection or transplantation is the only potential 
curative treatment for HCC patients. Although the mortality of HCC has significantly decreased with the development of surgical techniques, about $60 \%-100 \%$ of the patients suffered from HCC recurrence ultimately even after curative resection, and it has become the most important factor that limits the long-term survival of HCC patients. Ambudkar et al. (1999) and Bao et al. (2000) showed that existing liver cancer treatments, including loco-regional or systemic chemotherapy, fail largely due to the chemo resistance properties of cancer cells.

Doxorubicin is one of the most frequently used drugs in cancer chemotherapy. Clinically the drug is administrated intravenously. Both intravenous and intraperitoneal injections have been used in short term experiments in mice, whereas results of long term administration are preponderantly based upon intraperitoneal administration (Lenaz et al. 1972) and Deprez-de et al. 1990). Treatment by new specific antiangiogenic drug and monitoring such treatment need reliable standardized and useful predicative markers of antiangiogenesis (Uzzan et al. 2004). Such biomarker must be easily measurable, reflecting accurately the pathological process that it is designed to measure and must provide the clinician with an answer that can be easily interpreted (Li et al. 2000).

The advantage of nanocapsule is its ability to evade the first-pass metabolism, thereby effectively reducing the dosage required for therapy ( $\mathrm{Li}$ et al.2000). It was observed that cancerous tissues have leaky vasculature which allows the nanocapsules to reach the site without much hindrance (enhanced permeability and retention effect) unlike microcapsules. (Li et al. 2005). The aim of the current study was to evaluate in vivo the anti-tumor efficacy of silver nanoparticles conjugated with conventional chemotherapy drug doxorubicin for the treatment of liver cancer. This approach based on silver proposes a novel platform therapy with minimal toxicity and increased efficacy profiles for the destruction of hepatic cancer.

\section{Materials and Methods}

The present study was carried on 40 male albino mice of $8-10$ weeks of age weighing (20-25g). The animals were housed in plastic cages under the following conditions;

$12 \mathrm{hrs} \mathrm{dark} /$ light cycle $22 \pm 2^{\circ} \mathrm{C}$ and $50 \pm 10 \%$ humidity. The animals were randomly divided into 2 major groups:

Group A: 10 mice were used as a control

group

Group B: 40 mice have induced HCC by dimethyl aminoazobenzene (DABE. This group were subdivided into three sub-groups; sub group B - 1: 10 mice which 4-Characterization of the nanoparticles:

were not received any treatment, and were kept at room About $5 \mu \mathrm{L}$ of nanoparticles were dried overnight on environment and, sub group B - 2: 10 mice were injected a clean silicon wafer and subjected to gold sputtering to intraperitoneal with dose $50 \mathrm{mg} / \mathrm{kg}$ body weight of ensure electrical conductivity (JFC 1100E ion-sputtering doxorubicin only every day for 21days, sub group B - 3 : device; JEOL, Tokyo, Japan) and analyzed by field 10 mice were injected intraperitoneal with dose 50 emission-scanning electron microscopy (FE-SEM; FEI$\mathrm{mg} / \mathrm{kg}$ body weight of doxorubicin encapsulated by the SIRION, Eindhoven, The Netherlands). Similarly, the silver nanoparticles every day for 21days( Lai et al. 1988). sample was placed on a carbon-coated 300 mesh

\section{Histopathological Examination}

Parts of liver tissue from mice of each previous group were processed and examined by Hematoxylin and Eosin (H\&E) method (Lewis et al. 1994). The liver tissue was fixed at $10 \%$ formaldehyde, then dehydrated in ascending grades of alcohol, embedded in paraffin to produce paraffin block, then the blocks were cut into 3-4 $\mu \mathrm{m}$ thick sections and floated in water bath, and cleaned with xylene, then rehydrated in descending grades of alcohol. Sections were stained by hematoxylin-eosin stains.

\section{1-Preparation of the nanoparticles:} complexing agent were dissolved in $9.2 \mathrm{ml}$ distilled water in separate dry beakers. They were mixed together at $\mathrm{pH} 1.6-5.17$ that it was adjusted by using appropriate amounts of $\mathrm{NH}_{4} \mathrm{OH}$ solution. This solution was then heated on a stirring hot plate at $250 \mathrm{C}_{0}$ for 45 minutes. Heating the mixture led to the evaporation of water and dehydration followed by decomposition of the complexes silvers ions, foaming and formation of fluffy ultrafine powder of silver ( Zhou et al. 2006).

Initially, stock solutions of Heparin (HP) were prepared at concentration of $1 \mathrm{mg} / \mathrm{mL}$ in $1 \mathrm{M}$ sodium chloride. The process was carried out at $\mathrm{pH} 5.6$, taking into account the pKa values of HP. A silica template $(220 \pm 20 \mathrm{~nm})$ was chosen as the sacrificial core. Since it is negatively charged, positively charged HP electrostatic ally binds to it, forming the first layer. The template was incubated for 15 minutes followed by centrifugation at $4000 \mathrm{rpm}$ for 5minutes (MIKRO 200R; Hettich Zentrifugen, Tuttlingen, Germany) and washed thrice with pH 5.6 water ( Zhou et al. 2006).

\section{3-Drug-loading studies:}

Doxorubicin $(1 \mathrm{mg} / \mathrm{mL})$ was chosen as the model drug and $400 \mu \mathrm{L}$ was incubated in $200 \mu \mathrm{L}$ of capsules overnight in $\mathrm{pH} 8$ water at room temperature. The nanocapsules were then immersed in $\mathrm{pH} 5$ for 60 minutes layers to retain the loaded doxorubicin. Following this the sample was washed twice with distilled water and subjected to centrifugation at $2000 \mathrm{rpm}$ for 5 minutes to dhe unencapsulated drug. The amount of using a spectrophotometer (NanoDrop ND1000; Thermo Scientific, Wilmington, DE, USA) by measuring the absorbance of the supernatant at $496 \mathrm{~nm}$.

sample was placed on a carbon-coated 300 mesh

Silver nitrate $(0.7 \mathrm{gm})$ and citric acid $(4.2 \mathrm{gm})$ as

\section{2-Capsule fabrication:}


copper grid (Toshniwal Bros SR Pvt Ltd, Bangalore, India) for field emission-transmission electron microscopy.

\section{5-Drug release studies:}

Doxorubicin release studies were carried out in neutral \& acidic $\mathrm{pH}$ over a period of 48 hours. The supernatant was taken out at stipulated time periods $(0.5,1,2,4,8,16,24$, and 48 hours) and release rate was quantified by measuring the absorbance at $496 \mathrm{~nm}$ using the Nano Drop spectrophotometer.

\section{Biochemical Examination}

RT-PCR for AFP- mRNA and glypican 3- mRNA genes expression amplification and detection:

RNA extraction:

RNA was extracted from the serum of mice using QIAamp RNA blood mini kit, was purchased from QIAGEN, USA according to the manufacturer's instructions. Preparation of Full-Length First strand cDNA from RNA template using RevertAid $^{\text {TM }}$ First Strand cDNA Synthesis Kit.

\section{Reverse transcription:}

Reverse transcription reaction was carried out in a $20 \mu 1$ reaction mixture by using RevertAid ${ }^{\mathrm{TM}}$ First Strand cDNA Synthesis Kit Cdna Synthesis Kit\# K1621,\#1622, was purchased from MBI Fermentas, Lithuania according to manufacturer's instruction.

\section{RT-PCR amplification:}

To each PCR tube the following were added $5 \mu 1(0.25 \mu \mathrm{g})$ Template AFP- cDNA, $10 \mu 12$ Taq TM Green PCR Master Mix (2X) \{dNTPs [0.4 mM of each dATP, dCTP, dGTP, dTTP], 0.05u/ 1 Taq DNA polymerase and reaction buffer $\}$ \# k1081, was purchased from MBI Fermentas, Lithuania, $1.5 \mu 1 \quad$ AFP forward primer: 5 TGAGCTTCCTGCATTGGGAG - 3, $1.5 \mu 1$ AFP reverse primers: 5 - CCCGCCAGCATCATAGCTTA - 3 and deionized-RNase free water to final volume $20 \mu \mathrm{l}$. The reaction mixtures were gently vortexed, briefly centrifuged to collection all drops to the bottom of the tubes, then were placed in the thermal cycler (Little Genius, Bioer Co), The PCR mixture was subjected to 35 amplification cycles. PCR conditions were as follows: An initial denaturation $\left(94^{\circ} \mathrm{C}, 2 \mathrm{~min}\right)$, followed by 35 cycles of denaturation $\left(94^{\circ} \mathrm{C}\right.$, $1 \mathrm{~min})$, annealing $\left(52^{\circ} \mathrm{C}, 1 \mathrm{~min}\right)$, and extension $\left(72^{\circ} \mathrm{C}\right.$, $1 \mathrm{~min})$, with a final extension $\left(72^{\circ} \mathrm{C}, 7 \mathrm{~min}\right)$. To each PCR tube the following were added $5 \mu 1(0.25 \mu \mathrm{g})$ Template glypican-3- cDNA, $10 \quad \mu 12 \quad \mathrm{X} \quad$ PCR Master Mix $\{$ dNTPs [0.4 mM of each dATP, dCTP, dGTP, dTTP], $0.05 \mathrm{u} / 1 \mathrm{Taq}$ DNA polymerase and reaction buffer $\}, 1.5 \mu 1$ AFP forward primer: 5 CTGGTGACGGGATGGTGAAA- 3, $1.5 \mu 1$ AFP reverse primers: 5 - CTTAATGGTGGTGGGAGGAGG- 3 and deionized-RNase free water to final volume $20 \mu \mathrm{l}$. The reaction mixtures were gently vortexed, briefly centrifuged to collection all drops to the bottom of the tubes, then were placed in the thermal cycler (Little Genius, Bioer Co), The PCR mixture was subjected to 35 amplification cycles. PCR conditions were as follows: An initial denaturation $\left(94^{\circ} \mathrm{C}, 2 \mathrm{~min}\right)$, followed by 35 cycles of denaturation $\left(94^{\circ} \mathrm{C}, 1 \mathrm{~min}\right)$, annealing $\left(52^{\circ} \mathrm{C}, 1 \mathrm{~min}\right)$, and extension $\left(72^{\circ} \mathrm{C}, 1 \mathrm{~min}\right)$, with a final extension $\left(72^{\circ} \mathrm{C}, 7 \mathrm{~min}\right)$. To verify the successful preparation of mRNA and as positive controls, samples were detected for the presence of glyceraldehyde-3-phosphate dehydrogenase (GAPDH) mRNA. forward primer: 5 AGGCCGGTGCTGAGTATGTC - 3, reverse primers: 5 TGCCTGCTTCACCACCTTCT - 3. Reaction tubes containing no cDNA control template and without cDNA sample addition were included as negative controls for each PCR reaction.

\section{Detection:}

The amplicons were analyzed with $2 \%$ (wt/vol) ethidium bromide stained agarose gel. The bands were visualized on a $302 \mathrm{~nm}$ UV transilluminator (BIO-RAD, USA).The gel was examined for bands of 207 and $345 \mathrm{bp}$ as determined by the molecular weight marker (Gene Ruler TM 100bp plus DNA Ladder, ready-touse\#SM0323, was purchased from Fermentas, Lithuania) runs at the same time and then photographed using a digital camera .

\section{Results}

Drug release studies were carried out in acidic and neutral $\mathrm{pH}$ over a period of 48 hours and it was observed that $77 \%$ release was obtained in acidic $\mathrm{pH}$ as opposed to $64 \%$ in neutral $\mathrm{pH}$ (Figure 1). This increase in release percent in acidic $\mathrm{pH}$ makes it a better choice for use in cancerous cells owing to its more acidic nature. Subsequently, confocal laser scanning microscopy was used as the cell nucleus was stained with DAPI, which has an emission maximum at $461 \mathrm{~nm}$ (blue). On release of doxorubicin from the capsules after incubation with the cells for more than 30 minutes, the nucleus is found to be stained red with an emission maximum of $496 \mathrm{~nm}$ (Figure 5 [1B-3B]). Doxorubicin forms complexes with DNA by intercalation between base pairs, and inhibits topoisomerase II activity by stabilizing the DNAtopoisomerase II activity. After 5 hours of incubation, the cells lines show blebs which are indicative of apoptosis suggesting the cytotoxic activity of doxorubicin(Figur 5 ).

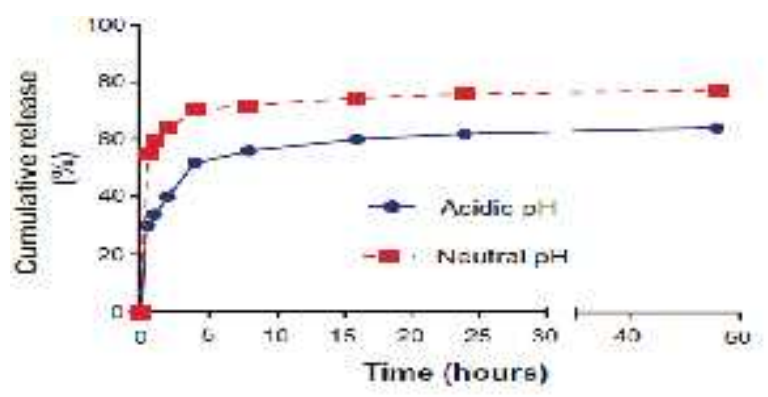

Figure(1): Drug release studies in acidic $\mathrm{pH}$ (4.8) and neutral $\mathrm{pH}$ (7.4)

Biodistribution studies were carried out to understand the pharmacokinetics of the nanocapsule-loaded doxorubicin and free doxorubicin. It is observed that over a period of 24 hours, the concentration of free doxorubicin reduces to $0.25 \mu \mathrm{g} \mathrm{mL}-1$, while that of nanocapsule-loaded doxorubicin is $0.75 \mu \mathrm{g} \mathrm{mL}-1$ in serum. This clearly 
suggests an increase in the circulation time of doxorubicin when it was loaded in nanocapsules (Figure 1). This can be due to the slow and complete release of doxorubicin from the capsules before being eliminated, and also due to the fact that the nanoparticles gets accumulated in the tumor tissues due to their enhanced permeability and retention effects. This increased circulation time can provide better efficiency of the drug in vivo.

\section{Histological results}

In the present work Histological examination was performed on all study groups and Coded $\mathrm{H}$ and $\mathrm{E}$ stained slides were examined microscopically by a single pathologist using a high power (magnification, $\times 400$ ), and at least five high-power fields were examined to detect histopathological changes: gp (A) (control); showed normal hepatic architectiure, gp (B-1), (That do not receive any treatment); showed less preserved hepatic architecture with focal cytoplasmic vaculation of hepatocyte, mild fibrosis and lymphatic infiltration, vascular degeneration and ballooning of hepatocyte with moderate fibrosis, areas of coagulative necrosis and various degree of dysplasia and finally $\mathrm{HCC}$, gp (B-2) (which treated by injected intraperitoneal with doxorubicin only); showed moderate lymphatic infiltration also moderate necrosis and moderate nuclear displeases (nuclear enlargement prominent nuclei), and the last part gp (B-3) (which treated by injected intraperitoneal with doxorubicin encapsulated by the silver nanoparticles); showed no fibrosis and no necrosis with relative chromatin distribution and relatively normal hepatocyte.

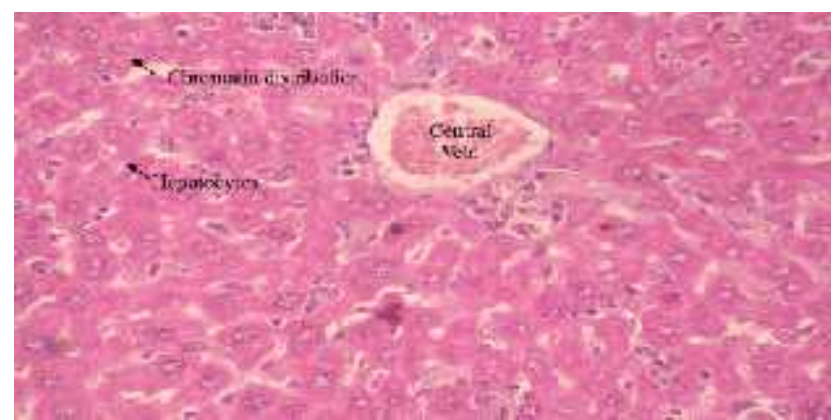

Figure(2): Control group with normal hepatocytes $(\times 400)$.

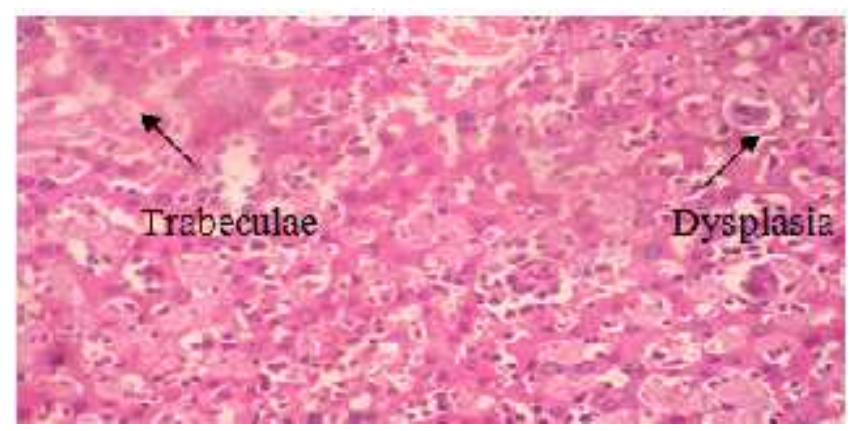

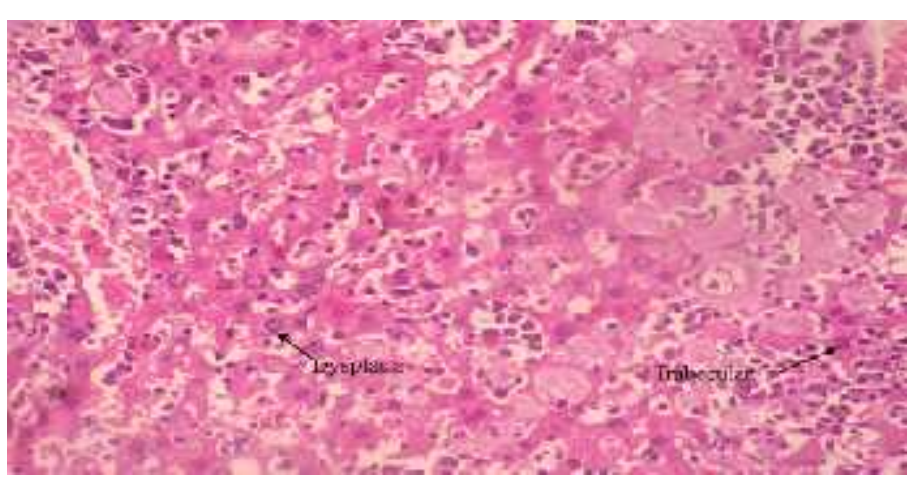

Figure(4): The group of doxorubicin reveals changes in pattern of chromatin distribution $(\times 400)$.

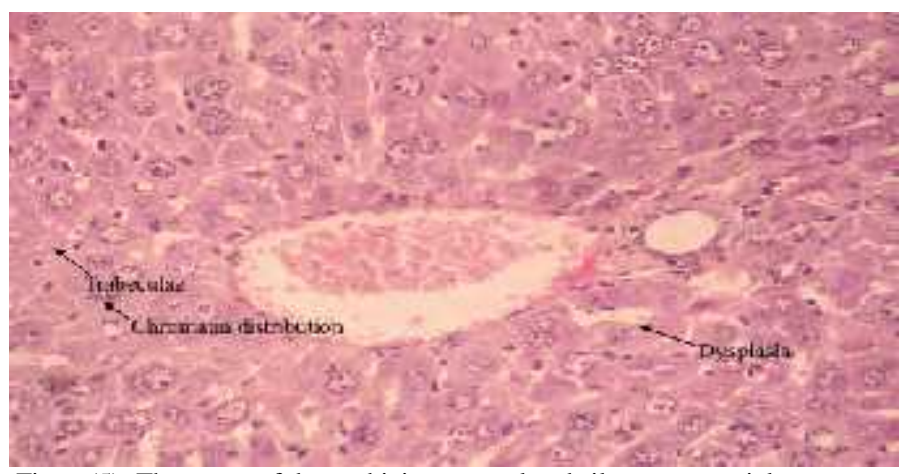

Figure(5): The group of doxorubicin encapsulated silver nanoparticles reveals change in pattern of chromatin distribution $(\times 400)$.

\section{Molecular results}

In the present study molecular study of AFP and Glypican-3 gene expression as a molecular diagnostic and prognostic markers for HCC revealed a significant increase in the expression of AFP-mRNA and glypican-3-mRNA genes at sub group $\mathrm{B} 1$ after administration of $\mathrm{DAB}$ as compared to group A, at the same time histopathological changes were also seen. Sub group B3 showed a relatively lower genes expression of AFPmRNA and glypican-3-mRNA sub group than B2 and these reduction had its impact on the histopathological findings. This result indicated that treatment with doxorubicin encapsulated silver nanoparticles showed promising way for treatment of HCC than traditional chemotherapeutic doxorubicin.

The data in the present study showed that during the whole course of experiment the histopathological changes were synchronized with the biochemical changes. Molecular detection of AFP-mRNA and glypican-3-mRNA genes expression using RT-PCR could be used as a diagnostic and prognostic predictor of HCC.

Figure(3): HCC group $(\times 400)$. 
Ammififiontion of $n R N A-A F T$ qmuc by RT-PR:R:

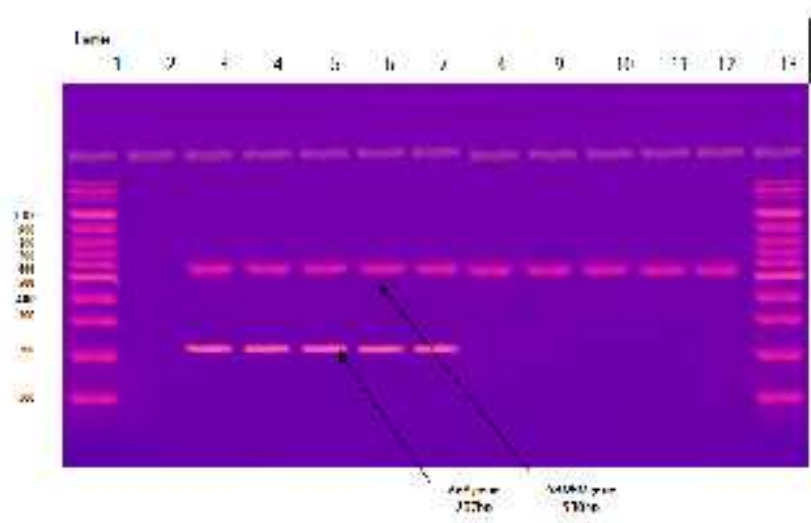

Figure (6): Ethidium bromide stained agarose gel showing bands of amplified PCR products of $m R N A-A F P$ gene of Sub group B 1; mice have induced HCC by DABE and have not received any treatment blood samples: Lane 1 and 13 marked the DNA marker, Lane 2 showing negative control (DNA nuclease free water), lane 3- 7 marked positive cases showing amplified bands of $207 \mathrm{bp}$ and lane 8- 12 marked negative cases of control group mice (530 bp representing $G A D P H$ gene as positive control).

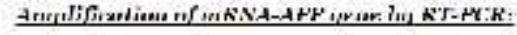

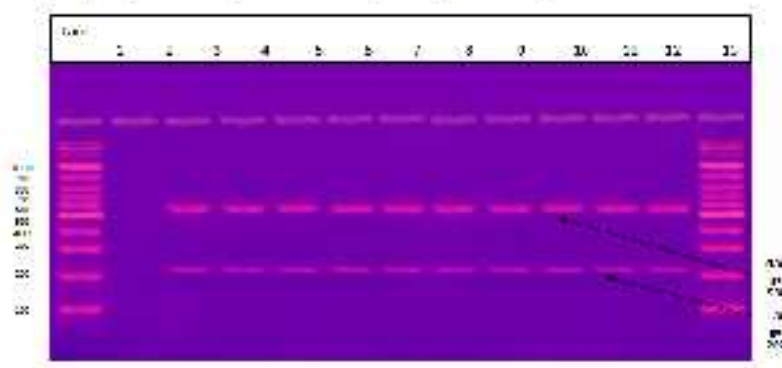

Figure (7): Ethidium bromide stained agarose gel showing bands of amplified PCR products of mRNA-AFP gene of Sub of group $\mathrm{B}-2$ : 10 mice were treated by injected intraperitoneal with doxorubicin blood samples: Lane 1 and 13 marked the DNA marker, Lane 2 showing negative control (DNA nuclease free water), , lane 3- 12 marked positive cases showing amplified bands of $207 \mathrm{bp}$. (530 bp representing GADPH gene as positive control).

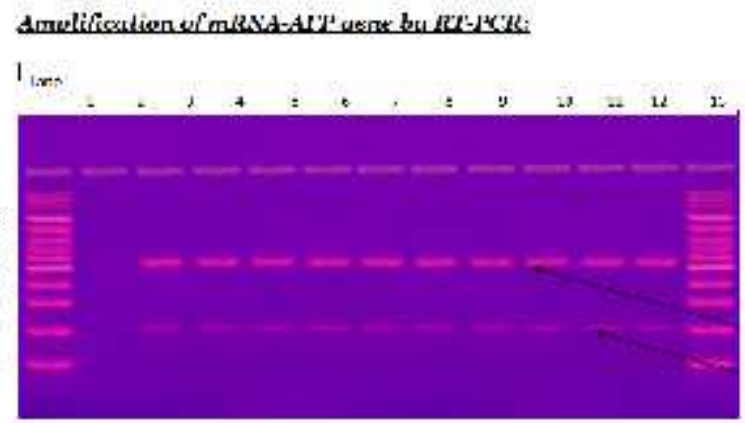

Figure (8): Ethidium bromide stained agarose gel showing bands of amplified PCR products of mRNA-AFP gene of Sub of group B - 3: 10 mice were treated by injected intraperitoneal with doxorubicin encapsulated by the silver nanoparticles blood samples: Lane 1 and 13 marked the DNA marker, Lane 2 showing negative control (DNA nuclease free water), , lane 3- 12 marked positive cases showing amplified bands of $207 \mathrm{bp}$. (530 bp representing GADPH gene as positive control).

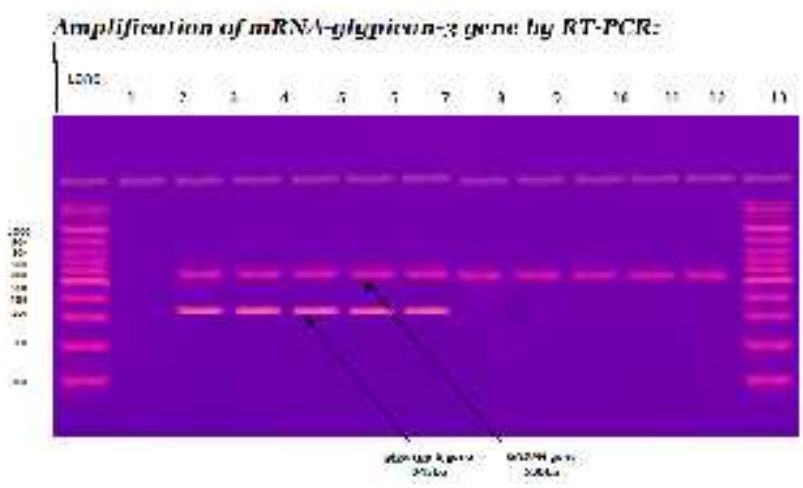

Figure (9): Ethidium bromide stained agarose gel showing bands of amplified PCR products of mRNA received any treatment blood samples: Lane 1 and 13 marked the DNA marker, Lane 2 showing negative control (DNA nuclease free water), lane 3- 7 marked positive cases showing amplified bands of $345 \mathrm{bp}$ and glypican-3 gene of Sub group B -1; mice have induced HCC by DABE and have not lane 8-12 marked negative cases of control group mice (530 bp representing GADPH gene as positive control).

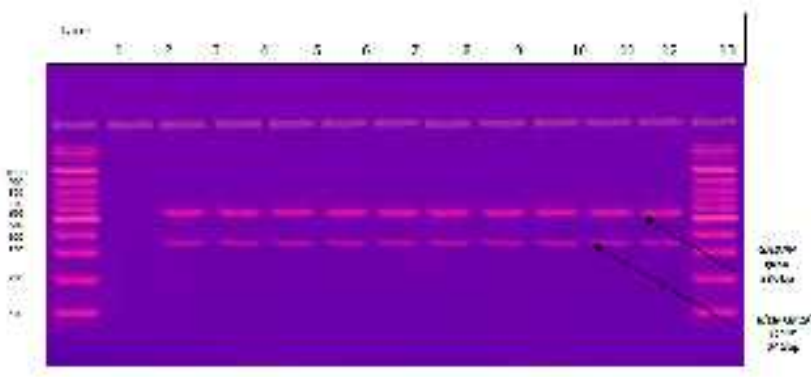

Figure (10): Ethidium bromide stained agarose gel showing bands of amplified PCR products of mRNA- glypican-3 gene of Sub of group B - 2: 10 mice were treated by injected intraperitoneal with doxorubicin blood samples: Lane 1 and 13 marked the DNA marker, Lane 2 showing negative control (DNA nuclease free water), lane 3-12 marked positive cases showing amplified bands of $345 \mathrm{bp}$. (530 bp representing GADPH gene as positive control).

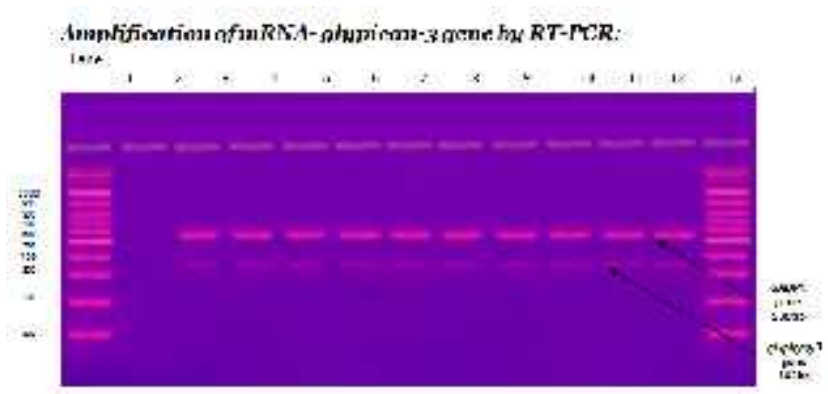

5xis Figure (11): Ethidium bromide stained agarose gel showing bands $\cdots$ of amplified PCR products of mRNA- glypican-3 gene of Sub of group B - 3: 10 mice were treated by injected intraperitoneal with doxorubicin encapsulated by the silver nanoparticles blood samples: Lane 1 and 13 marked the DNA marker, Lane 2 showing negative control (DNA nuclease free water), , lane 3- 12 marked positive cases showing amplified bands of $345 \mathrm{bp}$. (530 bp representing GADPH gene as positive control). 


\begin{abstract}
4. Discussion
Hepatocellular carcinoma (HCC) is known to be chemoresistant to anticancer drugs due to the multidrug resistant (MDR) transporters expression. Here, we compared in vivo the anti-tumor efficacy of doxorubicin- loaded silver nanoparticles versus free
doxorubicin. Although doxorubicin is commonly used for doxorubicin. Although doxorubicin is commonly used for
intra-hepatic artery delivery of chemotherapy for HCC (Lovet et al. (2002), its efficacy is rather low and has never shown significant and substantial benefit on tumor regression and overall survival (Krishna et al. 2000).
\end{abstract}

Anticancer drugs, even if they are located in the tumoral interstitium, can turn out to have limited efficacy against numerous solid tumor types, especially because cancer cells are able to develop mechanisms of resistance and evade chemotherapy (Tapiero et al. 1986). The multidrug resistance (MDR) phenotype, mainly due to expression of the MDR gene family encoding for the membrane proteins called Pglycoprotein (P-gp). Ambudkar et al. (1999) represents an important problem in chemotherapy. The
P- gp proteins are capable of extruding various generally positively charged xenobiotics, including some anticancer drugs, out of the cell via one ATP-dependent mechanism. The MDR gene family possesses two members in humans and three in rodents. However, one human gene (MDR1) corresponds to the two rodent genes (mdrla and mdrlb, alternatively referred to as mdr3 and mdr1 in mouse) which are functionally related to the MDR phenotype (Bao et al.2000).

Gene encodes a membrane glycoprotein that can account for some, but not all, forms of nonP-gp related drug resistance. Similar to P-gp, the MRP protein confers resistance to hydrophobic drugs by decreasing their intracellular accumulation via one ATP-dependent efflux mechanism (Lewis et al. 1994).Several strategies were investigated to overcome MDR:(i) chemical modification of drugs; (ii) co-administration of chemo sensitizing compounds generally acting as P-gp inhibitors; and (iii) the use of drug carriers such as microspheres, liposomes, or nanoparticles (Kellen et al. 1993, Zaman et al. (1994) and Zhou et al. 2006).

Nanoparticles may be defined as being submicronic $(<1 \mu \mathrm{m})$ and ultra dispersed colloidal systems, made of polymers. In vivo studies have demonstrated that intravenously injected nanoparticles are taken up by the liver after only a few minutes due to the opsonization process (Brigger et al. 2002. Furthermore, with nanoparticles, very encouraging results were obtained at the cellular level: efficient drug protection (Brigger et al. 2002), cell internalization (Couvreur et al. 1977) and Grislain et al. 1993), controlled release, or reversion of the MDR resistance. Cuvier et al. (1992) and Chavany et al. (1994) has been shown that doxorubicin-loaded nanoparticles of silver nitrate, were able to bypass in vitro the MDR resistance. Cuvier et al. (1992) and preliminary in vivo experiments gave promising results (Colin et al.1994,1997).The expected mechanisms were that doxorubicin loaded nanoparticles could enter the cells by an endocytotic pathway, thus by passing the P-gpdependent efflux, leading to an increased intracellular drug concentration and drug cytotoxicity. However, various investigations have shown that overcoming cell resistance resulted rather from the adsorption of nanoparticle onto the cell surface, thus increased doxorubicin diffusion than from a single endocytotic uptake. This mechanism was made easier by the formation of an ion pair between the drug and one of the polymer degradation products, allowing to shield doxorubicin's positive charge (Colin et al. 1994,1997).

In the present study, we have provided direct evidence that doxorubicin-loaded nanoparticles composed of heparin have higher anti-tumor cytotoxicity than the free form of doxorubicin on HCC cells. This observation was done first assessed in vitro on different human hepatoma cell lines that are well known as chemo resistant to MDR gene expression.

The higher efficacy of doxorubicin nanoparticles was further confirmed in vivo on the $\mathrm{X} / \mathrm{myc}$ transgenic murine model of HCC that was shown to over express the MDR related genes too. Therapy of HCC is rather inefficacious, and HCC tumors are well known as resistant to chemotherapeutic drugs, mostly because HCC cells are able to develop resistance mechanisms and to evade the effects of chemotherapy (Krishna et al.2000). HCC exhibits numerous molecular abnormalities, which may be involved in the process of HCC development and progression. Thus, it is important to identify accurate predictors of prognosis and a reasonable selection criterion that can be applied to patients with HCC, particularly with early stage $\mathrm{HCC}$, for rational treatment decisions remains a challenging task ( $\mathrm{Li}$ et al. 2000). During the diagnosis of HCC, a combination assay of at least two or three markers is recommended for a more sensitive and specific diagnosis of HCC. However, these traditional biomarkers do not reflect the biological features of the tumor or provide information about HCC behavior; thus, they do not allow the physician to accurately predict the outcomes of HCC patients. In the emerging era of new molecular targeted therapy for HCC, the evaluation of these novel agents will also require novel improvements in both the efficacy of the traditional biomarkers as well as other serological markers. In the present study molecular study of AFP and gly-3 genes expression as a molecular diagnostic and prognostic markers for $\mathrm{HCC}$ revealed a significant increase in the expression of AFP-mRNA and gly-3-mRNA genes at sub group B1 after administration of $\mathrm{DAB}$ as compared to group $\mathrm{A}$, at the same time histopathological changes were also seen.

The data in the present study showed that during the whole course of experiment the histopathological changes were synchronized with the biochemical changes. According to current results, there was an agreement with other studies done by several authors (Lai et al.1988, Li et al. 2000) and $\mathrm{Li}$ et al. 2005). Finally our study further support that 
molecular detection of AFP-mRNA and gly-3-mRNA genes expression using RT-PCR could be used as a diagnostic and prognostic predictor of HCC.

\section{Conclusion}

From the present study it could be suggested that therapeutic effect of doxorubicin encapsulated silver nanoparticles drug showed promising results for treatment of HCC compared to results obtained with doxorubicin drug. Encapsulated silver nanoparticles results in reduced tumor growth, and induction of apoptosis in the treated cells by enhancing delivery of chemotherapy and anticancer drugs with enhanced efficacy and fewer adverse effects.

\section{Recommendation}

From the present study it could be recommended that use doxorubicin encapsulated silver nanoparticles drug for treatment of HCC with increasing duration of treatment course. Also use of encapsulated silver nanoparticles for enhancing delivery of chemotherapy and anticancer drugs with enhanced efficacy and fewer adverse effects.

\section{References}

Ambudkar SV, Dey S, Hrycyna CA, Ramachandra M, Pastan I, Gottesman MM (1999). Biochemical, cellular, and pharmacological aspects of the multidrug transporter. Annu Rev Pharmacol Toxicol, 39: 361-398.

Anwar WA, Khaled HM, Amra HA, El-Nezami H, Loffredo CA (2008). Changing pattern of hepatocellular carcinoma (HCC) and its risk factors in Egypt: Possibilities for prevention. Mutat Res, 659:176-84.

Bao JJ, Lee BP, Stephens LC, Sahin AA, Van NT, Johnston DA, et al (2000). Elevated expression of hepatic proliferative markers during early hepatocarcinogenesis in hepatitis-B virus transgenic mice lacking mdrla-encoded P-glycoprotein. Mol Carcinog, 29:103-111.

Brigger I, Dubernet C, Couvreur P (2002). Nanoparticles in cancer therapy and diagnosis. Adv Drug Deliv Rev, 54:631-651.

Bruix J. Sherman M (2005). Practice guidelines committee, American association for the study of liver diseases. Management of hepatocellular carcinoma. Hepatology, 42:1208-1236.

Chavany C, Saison-Behmoaras T, Le Doan T, Puisieux F, Couvreur P, Helene C (1994). Adsorption of oligonucleotides onto polyisohexylcyanoacrylate nanoparticles protects them against nucleases and increases their cellular uptake. Pharm Res, 11:1370-1378.

Colin de Verdiere A, Dubernet C, Nemati F, Poupon MF, Puisieux F, Couvreur P (1994). Uptake of doxorubicin from loaded nanoparticles in multidrugresistant leukemic murine cells. Cancer Chemother Pharmacol, 33:504-508.
Colin de Verdiere AC, Dubernet C, Nemati F, Soma E, Appel M, Ferte J, et al (1997). Reversion of multidrug resistance with polyalkylcyanoacrylate nanoparticles: towards a mechanism of action. $\mathrm{Br} \mathrm{J}$ Cancer, 76:198-205.

Couvreur P, Tulkens P, Roland M, Trouet A, Speiser P (1977). Nanocapsules: a new type of lysosomotropic carrier. Fed Eur Biochem Soc Lett, 84:323-326.

Cuvier C, Roblot-Treupel L, Millot JM, Lizard G, Chevillard S, Manfait M, et al. (1992) Doxorubicinloaded nanospheres bypass tumor cell multidrug resistance. Biochem Pharmacol, 44: 509-517.

Deprez-de, Campeneere D, Jacnke R, Baudon H (1990). DNA. Anthracycline complexesII. Comparative study of the acute lesions induced in mice after intravenous administration of free \& DNA bound adriamycin. Eur J cancer, 16: 987.

Grislain L, Couvreur P, Lenaerts V, Roland M, DeprezDecampeneere D, Speiser P (1993). Pharmacokinetics and distribution of a biodegradable drug-carrier. Int J Pharm, 15:335-345.

Kellen JA (1993). The reversal of multidrug resistance in cancer (review). Anticancer Res, 13: 959961.

Krishna R, Mayer LD (2000). Multidrug resistance (MDR) in cancer. Mechanisms, reversal using modulators of MDR and the role of MDR modulators in influencing the pharmacokinetics of anticancer drugs. Eur J Pharm Sci, 11: 265-283.

Lai CL, Wu PC, Chan GC, Lok AS, Lin HJ (1988). Doxorubicin versus no antitumor therapy in inoperable hepatocellular carcinoma. A prospective randomized trial. Cancer, 62:479-483.

Lenaz L, Di Marco (1972). On the reported lack of effectiveness of daunomycin and adriamycin on solid tumor. Cancer chemother Rep, 56:431-2.

Lewis JV (1994). Illustrated Guide to Diagnostic Tests: Student Version. Springhouse, PA: Springhouse Corp (pub) P. 578-645.

Li H, Forstermann U (2000). Nitric oxide in the pathologenesis of vascular disease. J Pathol, 190:24454.

Li MS, Ma QL, Chen Q, Liu XH, Li PF, Du GG, et al (2005). Alpha-fetoprotein triggers hepatoma cells escaping from immune surveillance through altering the expression of Fas/FasL and tumor necrosis factor related apoptosis-inducing ligand and its receptor of lymphocytes and liver cancer cells. World J Gastroenterol, 11:2564-9.

Lovet JM, Real MI, Montana X, Planas R, Coll S, Aponte J, et al (2002). Arterial embolisation or chemoembolisation versus symptomatic treatment in patients with unresectable hepatocellular carcinoma: a randomised controlled trial. Lancet, 359:1734-1739. 
Parkin DM, Bray F, Feriary I, Pisani P (2000). Estamiting the world cancer burden: Globocan. Int $\mathbf{J}$ cancer, 94:153-156.

Tapiero H, Mishal Z, Wioland M, Silber A, Fourcade A, Zwingelstein G (1986). Changes in biophysical parameters and in phospholipid composition associated with resistance to doxorubicin. Anticancer Res, 6:649-652.

Uzzan B, Nicolas P, Cucherat M, Perret G (2004). Microvessel Density as a prognostic Factor in Women with breast cancer: A systematic Review of the Literature and Meta-Analysis. Cancer Res, 64: 2941-55.

Wild CP, Hall AJ (2000). Primary prevention of hepatocellular carcinoma in developing countries. Mutat Res, 462: 381-93.

Yang XR, XuY, YuB et.al (2010). High expression levels of putative hepatic stem/ progenitor cell biomarkers related to tumor angiogenesis an poor prognosis of hepatocellular carcinoma. Gut, 59:953-962.

Zaman GJ, Flens MJ, van Leusden MR, de Haas M, Mulder HS, Lankelma J, et al (1994). The human multidrug resistance-associated protein MRP is a plasma membrane drug-efflux pump. Proc Natl Acad Sci USA, 91: 88228826.

Zhou L, Liu J, Luo F (2006). Serum tumor markers for detection of hepatocellular carcinoma. World $\mathbf{J}$ Gastroenterol, 12:1175-81. 